\title{
Thoughts on the Application of Tax Big Data
}

\author{
Pei Gong \\ School of Automation Electrical Engineering, University of Science and Technology Beijing, Beijing, \\ China, \\ del_g_p@126.com
}

Keywords: application, suggestion, tax big data.

Abstract: Big data has been rapidly integrated into national governance, social economy and daily life, which is opening a major transformation of the times. In 2015, the Chinese State Council promulgated the "Program for Promoting the Development of Big Data". It has made clear that the key works are to accelerate the opening and sharing of government data, promoting the integration of resources and boosting the development of industrial innovation. The tasks, how to fulfill an effective job of the analysis and application of tax big data, and how to serve the economic social development as well as macro decision-making better, are urgent to be explored and tried. Starting from the function of taxation, this paper puts forward the initial direction of the application of tax big data.

\section{Introduction}

With the advent of the era of big data, a huge amount of information [1] is provided for deep mining and analysis. The convergence and integration of information technology and economic society has caused the rapid growth of data. The data has become the basic strategic resource of a country. The large number of data have a significant impact on the global production, circulation, distribution, consumption activities and economic operation mechanism, social life style and national governance capacity. Taxation is like a "barometer" of social and economic development. The tax big data covers the operating and financial data of the taxpayers, the core data of the taxation management, and the industry supervision data. At the same time, tax administration law and other regulations also ensure the timeliness and accuracy of the data updating. Wang Jun who is director of State Administration of Taxation said: "In the era of big data, those who can master the data and be proficient in use it will improve insight and occupy the commanding point". Taxation should actively comply with the changes of big data in the era. Revenuer need pay attention to the collection, analysis and use of data, insist on making data speak and improve the management, in order to promote innovation with data, improve the ability to use big data technology and analyze big data, Taxation is committed to play an important role in facilitating growth, investment and prosperity for all our citizens. It is to further enhance the basic, mainstay and guarantee the role of taxation in national governance, and to promote modernize China's system and capacity for governance. 


\section{The Current Situation and Problems of the Application of Tax Big Data}

\subsection{Current status of tax big data application in China}

In the development of taxation information construction, especially in the construction of the first, second and third phases of the Golden Tax Project, the tax authorities have implemented the information management of most taxpayers to form a large number of tax data. Through the construction of the comprehensive tax platform the tax authorities have mastered a certain amount of third-party tax-related information. At the same time, they have continuously explored and practiced the analysis and utilization of tax big data. They have achieved in effect analysis of preferential tax, joint between taxpayers' faith and incentives, between taxpayer's dishonesty and disciplinary mechanism. Domestic scholars have also carried out a series of theoretical studies around the deep utilization of tax big data. Some portray tax economic relations through the establishment of models and historical data; some use data warehouse technology and BP neural network model to predict tax revenue; some examine the relationship between tax revenue and GDP through integration third-party economic data. It can be said that the tax authorities and researchers have made a lot of efforts in the application of tax big data from the management and academic respectively. They have achieved certain results. However, in general, the application level of tax big data in China is still relatively backward, especially compared with the tax big data application in some developed countries.

\subsection{Current status of tax big data application in developed countries}

Developed countries started early in the application of tax big data. In 1995, the New Zealand Taxation Bureau implemented Customer Relationship Management under the help of IBM to establish a tax collection system with taxpayers as the center. In 1998, the California tax authorities used business intelligence technology to analyze more than 220 million tax data. In 2002, Washington tax authorities established a data warehouse, applying data mining technology for audit selection. Canadian tax authorities assess tax evasion suspicion of taxpayers through cross comparison of tax big data. Many countries have established a special the tax big data analysis agency, the US Internal Revenue Service established the Research, Analysis and Statistics Division to conduct research on econometric models, tax revenue projections, tax compliance, tax legislation analysis, economic development policy assessment, etc. The Royal Customs and Excise Department has expanded from simple forecasting of tax revenues to analyze related information of various types of taxpayers through the establishment of Knowledge, Analysis \& Intelligence Directorate, Data Laboratories, Digital Service Centers and Big Data Analysis Centers. The information of taxpayers can measure the loss of taxation, the development of industry, the general situation and forecast of current economic and social development status and trends in order to provide practical and feasible suggestions for decision-making.

\section{Suggestions on the Application of Tax Big Data in China}

\subsection{Response to social concerns actively and serve national governance}

At present, the number of Internet and mobile Internet users in China ranks first in the world. With the widespread use of new media such as SMS, WeChat and Weibo, the spread of social hotspot issues has also "plugged wings". The negative issues are spread very fast and the butterfly effect of 
rumor in internet is huge, so if social hot spot issues can't be responded timely and objectively, they will have a negative impact on national governance. Taxation is closely related to social and economic development. For example, the shadow of taxation can be found in false contracts of entertainment circle, collective price increase of hotel industry, price increase of imported milk powder, the house prices increase and many other social phenomena. They, price-tax-economy, are just like the three brothers accompanying each other, forming mutual transformation, interaction, mutual influence. The current taxation work must pay attention to hotspot issues of economic social development and public concerns. In addition, with information technology and the existing data, construction of a production and operation status model of industry concerned by the society is necessary. The cost, profit, tax burden and other indicators of controversial economic entities can be calculated by the model. The calculated exact quantitative tax conclusions reveal the economic root causes of the social phenomena. The propaganda and interpretation of the tax policies and regulations as well as economic phenomena guide market behavior and social psychological expectations to win the understanding and support from the social masses, and then improve the national governance.

\subsection{Focus on the effect of economic policy and serve the national strategy}

The world economy is now in profound adjustments and moving along a twisted path to recovery. It stands at a crucial juncture where new growth drivers are taking the place of old ones. As socialism with Chinese characteristics has entered a new era, the principal contradiction facing Chinese society has evolved, what now face is the contradiction between unbalanced and inadequate development and the people's ever-growing needs for a better life. The phenomena of short effective demand in the market, insufficient motivation in traditional industries, and insufficient investment in real economy are emerging. CPC Central Committee and the State Council have proposed Supply-side structural reform, the three national development strategy, which are the Belt and Road Initiative, the coordinated development of the Beijing-Tianjin-Hebei region, the development of the Yangtze Economic Belt, also Mass entrepreneurship and innovation, the "Made in China 2025" plan. Tax authorities and researchers should make full use of big data advantages, comprehensively analyze the tax economic indicators, such as major industry tax burden, export tax rebates, tax invoice flows, etc., Using tax efficiency analysis method measures whether there are tax excesses between key industries or between regions. Then taxation objectively reflects the national strategic economic policy effects. The application of tax big data can give advice to relevant policy support measures of relevant regions and industries in the next stage, so as to provide reference for leadership decision-making.

\subsection{Prejudge the situation of the economy operations and serve the macro decision}

The economic decides tax, the tax affects the economy. This view has been widely agreed by tax research scholars, Chinese and foreign scholars have studied the relationship between tax and economy from different angles. Ramsey [2] proposes the theory of optimal tax from the perspective of welfare economics in his published work "A Contribution to the Theory of Taxation”. Arthur Laffer's "Laffer Curve" vividly illustrates the interaction between tax revenue and economic development. Wang Feng-ying [3], An Ti-fu [4] and other domestic scholars analyzed the impact of tax burden on the economy from a quantitative perspective. Tax authorities and researchers should strengthen the analysis and study of the correlation between tax data and economic indicators, and utilize the general equilibrium analysis of different indicators to figure out the development of the industry from the perspective of tax revenue, to understand the employment situation from number of employees, to analyze the per capital disposable income from employee wages, to speculate the overall efficiency of industries from the quality of financial profit, to grasp the economic operation status and the 
transformation between new and old kinetic energy through taxation. They should pay attention to constructing the tax big data analysis application method system, comprehensively use statistical analysis, index analysis, measurement analysis and simulation analysis to simulate the quantitative model of tax economy. Exploring the establishment of Tax Economic Development Index \& Tax Economic Advance Index, etc., as well as waking up the "sleeping" data to continuously improve the service ability of the tax big data to social economy.

\subsection{Focus on tax collection and management and serve tax governance}

Big data is not only from the revolution of information technology, but it brings a challenge to the traditional mode of thinking in taxation in China. The impact on tax collection and management is huge and turning [5]. It requires tax authorities to change their working ideas actively and use advanced analytical techniques and big data to identify risks, manage resources, and clarify intervention goals better. In meanwhile, they should adhere to the needs of the taxpayers as a fundamental concern, based on the tax big data and relied on information approaches. The form of taxation transfers towards more digital tax service. The ways of tax management changes from prior administrative approval to the monitoring afterwards; from fixed mode to classification management, from non-differential management to risk management, from experience management to big data management. Tax authorities should encourage taxpayers to assess themselves, actively participate in tax co-governance, and further strengthen the modernization of the tax governance system and capacity for tax governance. They also should actively carry out the analysis of the subjective effort of the tax collection and management relying on the information management system such as the third phases of the Golden Tax Project and the performance management. Through macro and micro data, setting the indexes scientifically, conducting key indicator comparisons, rationally constructing an evaluation system, and timely discovering the problem of tax losses, tax fraud, overtax, etc. will improve the efficiency of collection and promote taxpayer compliance.

\section{Conclusion}

Big data has a profound impact on the current economic society. Tax big data, as an important part of big data, has its own unique characteristics. First of all, it runs through all the links and processes of social production, circulation and consumption. Secondly, because the tax-related activities accompanying economic activities are rapidly changing, tax big data is highly time-sensitive. Finally, there are a lot of implicit or explicit logical relationships in the tax big data, which makes it have strong self-filtering and error correction characteristics. The unique characteristics of tax big data provide a good precondition for us to carry out deep data analysis. The data is static, so we need to establish a data sharing mechanism as soon as possible, break the information island, use information technology such as Data mining and Blockchain, also apply economic analysis model concepts such as Computable General Equilibrium and System Dynamics Model of Tax Economy to deeply explore its intrinsic value, giving full play to the basic role of tax big data in national governance and tax governance.

\section{References}

[1] Sun Kai, Shen Yu-chi. Big Data-The Propeller for Building a Modern Tax Administration System. Taxation Research, 2015,(1)96-99.

[2] F. P. Ramsey, A Contribution to the Theory of Taxation, the Economic Journal, Vol. 37, No. 145 (Mar, 1927$)$, pp. 47-61

[3] Wang Feng-ying, Zhang Li-min. Empirical Study on Optimal Macro-Tax Burden In China-Based on the Raffle Curve 
Theory. Productivity Research, 2013, (2)16-18

[4] AN Ti-fu, LIN Lu-ning. Macroeconomic Tax Incidence: Positive Analysis and Proposed Tax Policy. Economic Theory and Business Management, 2002, (5)26-31.

[5] Wang Xiang-dong, Wang Wen-hui, Wang Zai-tang, Huang Ying. Opportunities and Challenges for the Transformation of China's Tax Administration Model under the Big Data Era. Contemporary Economic Research, 2014, (8)92-96. 